\title{
APLICAÇÃO DE ALGUNS HERBICIDAS NA CULTURA DA COUVE-FLOR (Brassica oleracea var. botrytis)*
}

\author{
KEIGO MINAMI ** \\ Oswaldo A. S. Di Giácomo *** \\ MASSAR KaTAYAMA *** \\ Clarice G. B. Demétrio $* * * *$
}

\section{RESUMO}

Foi conduzido na Área Experimental do Setor de Horticultura, DAH-ESALQ, Piracicaba, um experimento sobre o uso de alguns herbicidas na cultura da couve-flor (Brassica oleracea var. botrytis). Os herbicidas foram Dacthal (DCPA), Tenoran (cloroxuron), Afalon (linuron) e Ramrod (propacloro). O Dacthal, Ramrod e o Tenoran não foram fitotóxicos à couve-flor, enquanto que o Afalon foi muito fitotóxico. O herbicida que melhor resultado apresentou para a couve-flor foi o Ramrod.

\section{INTRODUÇÃO}

NISHI (1971) acha que o herbicida a ser usado na olericultura deve ser eficiente durante todo o ciclo da cultura e não deve deixar resíduos que possam afetar a cultura que vem depois. Por esta razão, muitos olericultores ainda fazem algumas restrições no uso de herbicidas.

Por outro lado, porém, a olericultura está deixando de ser uma simples horta e se transformando em cultura mais extensiva. Isso faz com que haja uma pressão na utilização de técnicas que possam diminuir o custo e a necessidade de mão-de-obra. Para o controle das plantas daninhas, muitos herbicidas são lançados no mercado. Dentre estes, somente alguns podem ser usados na cultura da couve-flor, sem muitos problemas.

* Entregue para publicação em 15/10/1976

* Professor Assistente do Dep. Agricultura e Horticultura

** Estagiários do Dept. Agricultura e Horticultura

* * Aluna do Curso de Pós-Graduação de Estatastica e Experimentação da ESALQ. 
FINLAYSON, CAMPBELL e ROBERTS (1975) obtiveram bons resultados na cultura da couve-flor, usando as misturas de trifluralina mais propacloro e nitrofen mais propacloro.

NISHI (1975) recomenda para as cricíferas, a trifluralina, nitrofen e prometrina.

Como pouca informação existe sobre o uso de herbicidas em couve-flor, foi feito um experimento nesse sentido, para as nossas condições.

\section{MATERIAL E MÉTODO}

O experimento foi conduzido no Campo Experimental do Setor de Horticultura (DAH-ESALQ), em Piracicaba. O experimento foi iniciado em $1 .^{\circ}$ de maio de 1975.

O solo da área é argiloso, com boa drenagem, 3,23\% de matéria orgânica, pH 6,7.

A cultivar utilizada foi a Bola de Neve. A cultura foi conduzida sob tratos fitossanitários normais e mais a aplicação de Wuxal e bórax.

A aplicação do herbicida foi feita com pulverizador costa e "jacto" com bico em leque. A aplicação foi logo após o transplante.

Foram testados os seguintes herbicidas:

Dacthal - pó-molhável, nome comum DCPA, dimetil tetraclorotereftalato.

Tenoran - pó-molhável, nome comum cloroxuron, 3-[p (p-clorofenoxi) fenil] 1,1 — dimetiluréia.

Afalon - pó-molhável, nome comum linuron, 3-(3,4-diclorofenil) - 1 metoxi - 1 metiluréia.

Ramrod - pó-molhável, nome comum propaclor , 2-cloro-N-isopropil acetanilida.

As plantas daninhas que ocorrem na área:

picão branco (Gallinsoga parviflora), trevo (Oxalis spp), capim marmelada (Brachiaria plantaginea), carrapicho-de-carneiro (Acanthospermum hispidum), mastruço (Lepidum satirum), serralha (Sonchus oleraceus), vassourinha (Lepidium virginicum) e tiririca (Cyperus rotundus).

O delineamento utilizado foi o bloco ao acaso, duas repetições, tendo cada parcela $8 \mathrm{~m}^{2}$, com 16 plantas, espaçadas de $1,40 \times 0,40 \mathrm{~m}$. 
Os tratamentos foram:
A - testemunha, 1 capina
B - testemunha, sem capina
C - Dacthal $16 \mathrm{~kg} / \mathrm{ha}$
D - Dacthal $8 \mathrm{~kg} / \mathrm{ha}$
$\mathrm{E}$ - Tenoran $10 \mathrm{~kg} / \mathrm{ha}$
$\mathrm{F}$ - Tenoran $8 \mathrm{~kg} / \mathrm{ha}$
G - Afalon $3 \mathrm{~kg} / \mathrm{ha}$
$\mathrm{H}$ - Afalon $2 \mathrm{~kg} / \mathrm{ha}$
I - Ramrod $3 \mathrm{~kg} / \mathrm{ha}$
$\mathrm{J}$ - Ramrod $2 \mathrm{~kg} / \mathrm{ha}$

\section{RESULTADO E DISCUSSÃO}

Os resultados de avaliação do controle de plantas daninhas, titotoxidez e peso médio por cabeça e peso médio por parcela, estão nos quadros I, II e III, respectivamente.

QUADRO I - Avaliação do controle das plantas daninhas (controle total $=10 \mathrm{e}$ nenhum controle $=1$ )

\begin{tabular}{ccc} 
Tratamento & \multicolumn{2}{c}{ Data de avaliação } \\
\hline & $20 / 05$ & $20 / 06$ \\
A & 7,0 & 2,5 \\
B & 7,5 & 4,5 \\
C & 7,0 & 3,5 \\
D & 7,0 & 2,5 \\
E & 8,0 & 7,0 \\
F & 8,0 & 6,0 \\
G & 8,0 & 6,5 \\
H & 8,0 & 6,0 \\
I & 9,0 & 7,0 \\
J & 9,0 & 7,0 \\
\hline CV & & 21,29 \\
$\Delta$ (Tukey, 5\%) & 6,08 & 4,54
\end{tabular}


QUADRO II - Avaliação da fitotoxidez (1 - sintoma de fitotoxidez ou morte das plantas e 10 - ausência de sintoma de fitotoxidez).

\begin{tabular}{cccc} 
Tratamentos & \multicolumn{3}{c}{ Data de avaliação } \\
\hline & $13 / 05$ & $27 / 05$ & $17 / 06$ \\
A & 9,0 & 10,0 & 10,0 \\
B & 7,5 & 10,0 & 10,0 \\
C & 7,0 & 10,0 & 10,0 \\
D & 7,0 & 9,5 & 9,5 \\
E & 6,0 & 9,5 & 10,0 \\
F & 6,5 & 9,0 & 10,0 \\
G & 3,5 & 3,0 & 4,0 \\
H & 5,0 & 6,5 & 8,5 \\
I & 7,5 & 10,0 & 10,0 \\
J & 6,5 & 10,0 & 10,0 \\
\hline CV & & & 10,37 \\
$\triangle($ Tukey - 5\%) & 7,96 & 6.65 & 3,87
\end{tabular}

QUADRO III - Efeito dos tratamentos sobre o peso médio de cada cabeça $(\mathrm{kg})$ e peso médio por parcela $(\mathrm{kg})$.

\begin{tabular}{ccc}
\hline Tratamento & Peso por cabeça & Produção/parcela \\
\hline A & 0,531 & 8,25 \\
B & 0,625 & 10,25 \\
C & 0,518 & 8,85 \\
D & 0,513 & 6,90 \\
E & 0,661 & 10,60 \\
F & 0,631 & 10,40 \\
G & 0,595 & 6,25 \\
H & 0,685 & 8,20 \\
I & 0,712 & 11,80 \\
J & 0,651 & 11,75 \\
\hline CV & & 14,52 \\
$\triangle$ (Tukey, 5\%) & 5,11 & 5,49
\end{tabular}


A cultura da couve-flor também, como o repolho, é sensível ao afalon (Quadro II). Para os demais herbicidas (Dathal, Tenoron e Ramrod), não sofreu quaisquer danos.

A avaliação de 13/05 é devida mais ao estado das mudas que ainda sofrem as conseqüências do transplante do que propriamente efeito dos herbicidas.

O controle das plantas daninhas também foi eficiente, usando-se os herbicidas, com exceção ao Dacthal que se mostrou ineficiente (Quadro I). A causa da baixa taxa de controle deste herbicida, talvez se deva às baixas temperaturas reinantes na época, pois, WAYNE e WAX (1970) afirmam que a ação do Dacthal cai muito quando é aplicado em condições de baixa temperatura e umidade relativa baixa.

O Ramrod, além de apresentar boa eficiência no controle dos matos e baixa toxidade à couve-flor, foi o que deu os melhores resultados quanto ao peso médio por cabeça e produção total por parcela (Quadro III).

\section{CONCLUSÃO}

Para as condições do experimento, conclui-se que:

a. O Afalon é muito tóxico à couve-flor e o Dacthal, Tenoran e Ramrod, não apresentam nenhum problema de fitotoxidade.

b. O Tenoran, Afalon e Ramrod deram bom controle às plantas daninhas, menos o Dacthal, que foi ineficiente.

c. O Ramrod se apresenta como um bom herbicida para a cultura da couve-flor, pois não é fitotóxico e tem boa eficiência no controle das plantas daninhas e as parcelas por ele tratadas foram as que apresentaram as melhores produções, tanto em termos de área como por cabeça.

\section{SUMMARY}

APPLICATION OF SOME HERBICIDES IN CAULIFLOWER (BRASSICA OLERACEA VAR. BOTRYTIS) CROP

An experiment about herbicide use on cauliflower (Brassica oleracea var. botrytis) crop was conducted in the Experimental Field of Horticulture Section DAH-ESALQ, Piracicaba, Brazil. It was tested Dacthal (DCPA), Tenoran (chloroxuron), Afalon (linuron). and Ramrod (propachlor). Dacthal, Ramrod and Tenoran were not fitotoxic to cauliflower, and Afalon was very toxic. The herbicide that gave the best results to cauliflower was Ramrod. 


\section{LITERATURA CITADA}

FINLAYSON, D.G., C.J. CAMPBELl e H.A. ROBERTS. 1975. Herbicides and inseticides: their cmpatibility and effects on weeds insects and earthworms in the minicauliflower crop. Annals of Appl. Biology 79: 95-108.

NISHI, S. 1971. Evoluction of candidate pesticides. (C-IV) Herbicide: Chemical control of weeds in vegetable fields. Japan Pesticide Information 8: 4-35.

NISHI, S. 1975. Evaluation of candidate pesticides (C-IV) Herbicides: Vegetable fields. Japan Pesticide Information 25: 16.

WAYNE, C.C. e L.M. WAX. 1970. Factors influencing the phytotoxicity of chloroxuron. Weed Science 18: 98. 